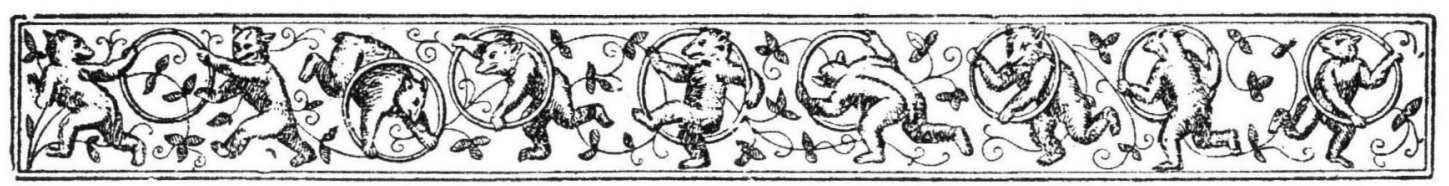

\title{
Iets over den schilder Benjamin Bolomey
}

DOOR

D. S. VAN ZUIDEN.

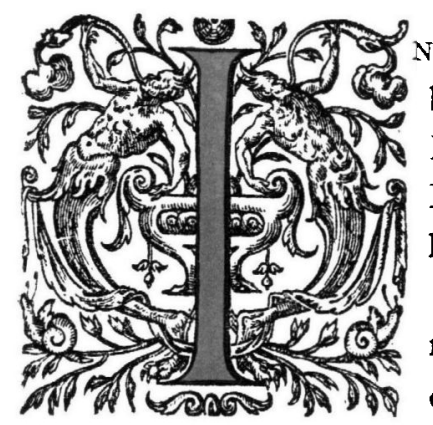

Oud Holland Igor publiceerde Dr. A. BREDIUs het belangrijkste uit de notulen der Haagsche Confrerie van Pictura, waarbij hij ook eenige mededeelingen deed over Benjamin Samuel Bolomey, die ik nu in de gelegenheid ben aan te vullen.

Bolomey, die zijn eerste opleiding te Parijs genoten had, kwam in 1763 in Den Haag, waar hij met de dochter van den bekenden boekhandelaar PIERRE Gosse den Sen November 1767 in de Fransche Kerk in het huwelijk trad. ${ }^{1}$ )

Erg gelukkig was dit huwelijk niet, zooals wij zullen zien.

Reeds drie jaren nadat hij als nieuwe leerling van Pictura was ingeschreven, vinden wij van hem het volgende contract, dat ons een blik doet werpen op zijn werk en ons iets vertelt over het ontstaan van de prent vermeld bij MULLER onder No. 4I 70

2) 2 Juin 1766

\section{Furent présent etc.}

Sieur Benjamin Bolomey, peintre, d'une part et Sieur Antoine Duboulois, graveur d'autrepart, demeurant présentement tous deux à la Haye, lesquels déclarent étre convenues ensemble de la manière suivante scavoir; que le dit Sieur Duboulors s'engage par ces présentes de poursuivre la gravure de la planche du tableau allégorique, peint par le dit Sr. Bolomey à l'évènement de l'anniversaire de Son Altesse le Prince d'Orange et commencé par le Sr. Bolly, que le dit Duboulois s'engage en outre de travailler à la gravure de la ditte planche de façon quelle

1) Huwelijksvoorwaarden 7 November bij Notaris J. G. vaN ALPHEN. Testament 20 April I 775 bij Notaris J. A. Potier (3869).

2) Protocol van Notaris A. OsNonr (3673).

Oud-Holland, 1917. 
dura être finie dans le courant du mois de Mai de l'année 1767 pour que le dit Sr. BolOMEY puisse tenir sa parole vis à vis du publique.

Par contre le dit Sr Bolomey s'engage à payer au dit Sr. Duboulors pour la gravure de la ditte planche jusqu'a son entiere perfection la somme de mille florins, payable en trois termes, scavoir six mois après la date des présentes fl I 300 , la somme de fl 400 lorsque la dite planche sera entiëremen finie et trois mois après la somme restante de $\mathrm{fl} 300$.

Sauf néanmoins qu'en cas que le dit Sr. Duboulors se trouvoit dans le cas de quitter La Haye, après que la dit planche sera finie, que dans ce cas le dit Sr. Bolomey sera obligé, de payer au Sr. Duboulois la somme alors restante.

Le dit Sr. Bolomey en outre s'engage de faire le portrait du Sr. Duboulors et son épouse, sans que le dit Sr. Duboulois sera obligé de rien payer pour ces dits pourtraits.

Pour l'acclompissement etc. etc.

Zooals uit deze acte blijkt begonnen dus toen reeds zijn werkzaamheden voor het Stadhouderlijk Hof waarvan verschillende geschilderde portretten en gegraveerde prenten het resultaat geweest $z i j n$. Eene serie der laatste vinden wij aangekondigd in eene advertentie in de Haagsche Courant van Zaterdag 4 Febr. 1792 als uitgegeven door P. F. Gosse.

Het zijn de afbeeldingen van WILLEM V, zijne vrouw, de erfprins met zijn vrouw, prins WILLEM GEORGE FREDERIK, prinses LOUISE met haar echtgenoot den erfprins VAN BRUNSWIJK, en dan de prinses van NASSAU-WEILBURG met hare schoonmoeder. De advertentie leert ons - wat onder de prenten niet vermeld staat - dat zij gemaakt zijn naar portretten van TischBEIN. Zij kosten 2 gulden, gekleurd 5 gulden.

Van zijn andere portretten vinden wij de volgende vermeld in een advertentie in de Haagsche Courant van 18 Jan. 1790 , nml. die van P. Nieuwland, W. DE Koning, B. Frieswijk, en D A. Reguleth, Predikanten te Amsterdam en J. ScharP Predikant te Rotterdam, die werden aangekondigd als verkrijgbaar voor 25 stuivers per stuk bij de boekhandelaren THIERRY EN MENSING.

Omtrent zijn levensomstandigheden nog het volgende:

In het jaar 1769 huurt hij 2 I Aug. ${ }^{1}$ ) een huis op de Nieuwe Haven voor de vrij aanzienlijke som van $f 450$ per jaar.

In 1784 woonde hij in de Wagenstraat. ${ }^{2}$ ) Toen was het evenwel met zijn huwelijksgeluk reeds treurig gesteld. Bij vonnis van Io Juli 1783 van het Hof van Holland, had zijn vrouw verlof gekregen, tegen haar man te procedeeren, van wien

1) Protocol van Notaris J. A. Porter. (3868)

2) Protocol van Notaris I. v. D. Watering, 25 Mei 1784 (4554), 
zij scheiden wilde. Hiertoe had zij verschillende getuigen verklaringen noodig, die haar zooals hieronder blijkt, gegeven werden.

Bij acte van 5 Januari 1783 (Notaris J. vaN NEE) geven verschillende personen toch getuigenis van de wijze waarop hij zijn vrouw behandelde; zoo verklaarde MARIA CANDELAaR huisvrouw van CASPAR BOOT,

dat zij in de maand November 1769 als keukenmeid zijnde komen wonen, en vervolgens als kindermeid gediend heett ten huyze van de vrouwe requirante. (V. Gosse) en aldaar gewoond hebbende tot Augustus 1777 heeft ondervonden, dat er gestadige oneenigheden tusschen BENJAMIN BoLOMEY en zijn vrouw hebben plaats gehad; dat die oneenigheden dikwijls met scheldwoorden van wegens den Heer Bolomey tegen zijn vrouw zijn gepaard geweest, en dat zij deposante otschoon de Fransche taal niet volkomen magtig egter meer dan eens zeer duydelijck heeft verstaan, dat de heer BoLOMEY zijn vrouw heeft gescholden voor een foutre de canaille, saloppe, monstre en diergelijke andere scheldwoorden.

Verder verhaalt de tweede comparante HELENA DE WITT, jonge dochter dan nog een aantal voorvallen, waarbij zij getuige was, hoe BOLOMEY zijn vrouw mishandelde om dan nog erger dingen te vertellen en wel "dat het eindelijk een waarheijd is, dat zij deposante met gemelde heer BoLOMEY op een Zondag alleen te huys zijnde, als zijnde de vrouwe requirante door haere ouders met een koets afgehaald, het is gebeurd, dat gemelde heer BoLomey haar deposante heeft gelast koolen op het vuur te gooien, dat zij deposante zulks doende gemelde heer BoLomEY welke aan den haard zat, haar deposante op eene zeer ombetamelijke wijze heeft aengetast zeggende: "wat ben je een lieverdje", dat de deposante deswegens haere verontwaardiging op een klaere wijze aen gemelte heer BOLOMEY hebbende getoond, dezelve haar deposante heeft gelast het theewater te brengen, dat zij deposante zulks gedaen hebbende, gemelde heer BoLOMEY haer deposante op eene zeer onbetamelijke wijze heeft aangetast : haer zeggende, dat zij zoo wel gemaakt was, dat hij haer beenen wilde teykenen, dog dat zij deposante daarop in sterke bewoordingen haer ongenoegen andermael te kennen gegeven hebbende, dezelve aen haer deposante heeft gezegd, dat het zoude zijn om er modelien na te schilderen noemende tegelijk een vrouw, welke hij zeyde, dat zeer schoon was en veel geld had gewonnen met zig door voorname meesters als een model te laten schilderen, en thans in een klooster was".

De scheiding vond natuurlijk plaats; hiervan werd bij acte een accoord gemaakt, tusschen PIERrE Gosse en BOLOMEY.

Gosse ontslaat hierbij BOLOMEx van de betaling van 400 gulden alimentatie kosten aan zijn vrouw en kinderen hem opgelegd door het Hof van Holland.

GossE verbindt zich daarentegen zijn dochter en kleindochter te onderhouden waartegen BOLOMEY afstand doet van $\mathrm{Al} 5000$ hem bij zijn huwelijk toegekend en ook van zijn aandeel in den handel van de drukkerij te Londen, zijn vierde part in de Encyclopedie d'Yverdon etc.

Na Gosse's dood zal diens vrouw MARGUERITE KOLB de alimentatie moeten voortzetten.

Nog even voor zijn vertrek naar $Z$ witserland passeerde hij 25 Mei I79I voor den Notaris E. SCHLUndT Bodies zijn testament, waarin hij tot erfgenamen van zijn vermogen, dat nog geen 20.000 gld. groot was, stelt zijn tweekinderen Pierre Francois Louis en Frederique Henriette Jacoba Bolomey.

Den I9 December I8I9 stierf Bolomey te Lausanne. 


\section{KORTE MEDEDEELINGEN.}

\section{CHLAUS BELLECHIN, CONTERFEYR.}

In Oberkammerjunker $\mathrm{Kn} \dot{\mathrm{u}} \mathrm{th}$ 's Rechnungen von $1670-1699$ die im Reichsarchiv in Kopenhagen beruhen, findet sich unter dem 27 februar 1675 folgender Vermerk :

Chlaus Bellechin, Conterfeyr, for 6 smaa Stycher ${ }^{3}$ ) 20 Reichst. Danach hat sich ein, soweit ich sehe, bisher nirgends erwähnter Conterfeyer (Porträt oder Bildnis maler) $\mathrm{Ch} l$ a u s Bellech in 1675 in Kopenhagen aufgehalten, wo er 6 kleine Stücke verkaufte.

Nach dem Allg. Lexicon der Bild. Künstler gab es mehrere Künstler namens B ell e ki n (Belkin, Belle qui n). Von dem holländischen Maler und Graveur in Perimutter und Horn, Cornelis Bellekin, der wahrscheinlich in Amsterdam geboren wurde und dort I664 einen Schüler annahm, haben sich $z$ wei Gemälde erhalten, eins in der Ermitage in Petrograd, ein zweites in der Sammlung Bredius im Haag. Beide stellon Kirmessen mit gut gemalten Figuren und in feinem, grauen Ton dar. Beide Bilder sind: C. B el $\mathrm{k}$ i n bezeichnet. Da mehrere seiner Verwandten sich ebenfalls mit der Kunst des Perlmutterschnitts befasst haben, so sind nach dem Allg. Lex. - die nur mit dem Familiennamen bezeichneten geschnittenen Nautilus schalen nicht unbedingt ihm zuzuschreiben. Nach Auffindung der urkundlichen Notiz über den bisher unbekannten $\mathrm{Cla}$ a $\mathrm{B}$ ellechin ergibt sich die Möglichkeit, dass sie ihm zuzuweisen sind. Ferner ist es sehr wohl möglich, dass auch die weiteren $\mathrm{B}$ el le ki in $\mathrm{f}$ bezeichneten Arbeiten, die bisher ebenso wie das Bild in der Ermitage und in der Sammlung B redi u dem Cornelis Bellekin zugeschrieben wurden, z. B. die Pokale im grünen Gewölbe zu Dresden und die Arbeiten in den Sammlungen $P$ ierpont Morgan in London und Six in Amsterdam dem um dieselbe Zeit lebenden $\mathrm{Cla}$ u $\mathrm{Bellechin} \mathrm{gehören.} \mathrm{Von} \mathrm{Cla}$ us $\mathrm{B}$ elle $\mathrm{ch}$ in lässt sich auf Grund des urkundlichen Belegs vorlaüfig nur sagen, dass er 1675 in Kopenhagen nachweisbar ist. Die 6 "Smaa Stycher" die er für 20 Reichstaler dem dänischen Könige verkaufte, können auch kleine in Perlmutter geschnittene Darstellungen gewesen sein. DR. HARRY SCHMIDT.

\section{HOE JORIS VAN DER HAGEN BETAALD WERD.}

Het is niet altijd gemakkelijk er achter te komen, hoe onze XVIle eeuwsche schilders betaald werden. Onze zoo incomplete archieven, geven daarover maar zelden uitsluitsel. Maar zelden zijn er zoovele notariëele acten over dit onderwerp verleden als van Rembrandt, waaruit wij leerden dat hij f I600.-- voor de Nachtwacht, f 500.- - voor een deftigr portret kreeg.

Er bestaat echter een soort korte aanteekeningen van kleine rechtszaken, Schepen rollen, die de meest verschillende namen dragen (te Amsterdam echter tot 1680 geheel ontbreken!!) waaruit een enkele maal een lichtstraal ontvonkt over dit onderwerp. Er hoort veel geduld toe, de honderden registers van dien aard te doorloopen en lang duurt het eer men een schildersnaam ontdekt. Toch heb $i k$ er veel uit geleerd. In den Haag zag ik er uit, hoe de arme $v$ a $n$ B e y e re $n$ voortdurend geplaagd en vervolgd werd door bakkers, brouwers en andere leveranciers. Te Haarlem was het met Frans Hals al evenzoo; ik hoop daarover eerlang iets te berichten. Te Dordrecht was de oogst schaars. En het is juist over den Haagschen schilder van de r $\mathrm{H}$ a ge n, die. te Dordrecht familie woonen had, dat de Binnengedingh-Rollen een kleine kunstbistorische bijdrage opleverden.

Joris van der $\mathrm{H}$ agen zond, evenals andere schilders, zijne stukken ,in commissie" naar andere steden. I) Zoo had hij ook zes stukken aan een kunstkooper? te Dordrecht ten verkoop gezonden. Blijkbaar liet de man niets van zich hooren en nu laat onze schilder hem manen om zijn geld. En het schijnt, dat va n der $\mathrm{Ha}$ ge n genoegen nam met 76 Gulden voor die zes stuks. Hier volgt de aanteekening in zijn geheel. Er is geen "vervolg" zoodat de man na deze aanmaning wel betaald zal hebben.

6 Maart 1656 . Hendricx en (dit staat er duidelijk) van de r $\mathrm{Hag}$ a $\mathrm{n}$ als last en procuratie hebbende van $\mathrm{J}$ oris $\mathrm{v}$ an der $\mathrm{H}$ ag en eyscher

contra

Floris Maertensz Houckste e $\mathbf{n}$ gedaechde, Eyscht betaling van 76 gulden over 6 stucken schilderije bij den voor:z. Joris van der $H$ age $n$ aen gede gesonden omme te vercoopen. Binnen-Gedinghen, Dordrecht,

1) Kleine stukken.

2) GODFRIED SCHALCKEN zond ze wel naar Parijs en reeds GoltziUs zond zijne prenten naar Frankrijk en Engeland.

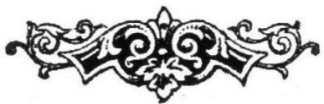

